\title{
QUALIDADE ÓSSEA, EXCREÇÃO MINERAL E DIGESTIBILIDADE DA MATÉRIA SECA DE POEDEIRAS SEMIPESADAS ALIMENTADAS COM CAULIM NO FINAL DO CICLO PRODUTIVO
}

\author{
(Bone quality, mineral excretion and dry matter digestibility of semi-heavy layers fed \\ with kaolin at the end of the production cycle)
}

Túlio Leite Reis ${ }^{1}$, Juan Carlos Palomino ${ }^{1}$, Felipe Dielis², José Evandro de Moraes ${ }^{3}$, Carla Cachoni
Pizzolante ${ }^{3}$, Ligia Fátima Lima Calixto ${ }^{2}$,

\begin{abstract}
${ }^{1}$ Universidade Federal Rural do Rio de Janeiro, Campus de Goytacazes, Rio de Janeiro, Brasil, ${ }^{2}$ Universiade Federal Rural do Rio de Janeiro, Seropédica, Rio de Janeiro, Brasil, ${ }^{3}$ Instituto de Zootecnia, Nova Odessa, São Paulo, Brasil
\end{abstract}

\section{Corresponding author: tulioreis@hotmail.com}

RESUMO: O caulim adsorve toxinas e patógenos no TGI permitindo maior digestão e absorção de nutrientes, podendo propiciar melhor qualidade óssea de poedeiras na fase final de produção. Todavia a adsorção de minerais, bem como a redução da digestibilidade da ração, também podem ser observadas, dependendo do nível de inclusão. Objetivou-se estudar a qualidade óssea, a excreção mineral e a digestibilidade de matéria de seca de poedeiras semipesadas alimentadas com rações contendo diferentes níveis de caulim. Foram alojadas 144 galinhas em delineamento inteiramente casualizado, em seis tratamentos: controle (sem a inclusão do aditivo); e inclusão de $1,2,3,4$ e $5 \%$ de caulim na dieta. Na $85^{a}$ semana de idade das aves foram mensuradas a digestibilidade aparente da matéria seca da ração (Digap), a excreção e retenção de matéria mineral, e a excreção de cálcio e fósforo. Para qualidade óssea foram mensurados o índice Seedor, e a matéria mineral e resistência a quebra da tíbia. Verificou-que a Digap e a excreção de matéria mineral pioraram $(P<0,05)$ com a maior concentração de caulim na ração. A retenção de matéria mineral se comportou de maneira quadrática, não houve diferença significativa $(P>0,05)$ na excreção de cálcio e fósforo. $O$ índice de Seedor aumentou de maneira linear $(P<0,05)$, não houve diferença significativa para os demais parâmetros ósseos $(P>0,05)$. A inclusão de caulim favoreceu a retenção de minerais e a qualidade óssea em galinhas poedeiras no final do ciclo produtivo, não promovendo alteração na retenção do cálcio e do fósforo e reduziu a digestibilidade da ração.

Palavras-chave: Argila; cálcio; fósforo; índice de Seedor; resistência óssea.

ABSTRACT: Kaolin adsorbs toxins and pathogens in the gastrointestinal tract allowing greater digestion and absorption of nutrients, improving better bone quality in laying hens in the final production stage, but adsorption of minerals, reduced feed digestibility, can also be observed, depending on the level of feed clay inclusion. Therefore, the objective of this study is to verify the inclusion of kaolin in the diet of semi-heavy laying hens at the end of the production cycle and its influence on the apparent digestibility of dry matter, mineral retention and excretion and bone quality. 144 hens were housed in a completely randomized design, in six treatments: control (without the inclusion of the additive); and inclusion of 1, 2, 3, 4 and $5 \%$ of kaolin in the diet. At 85 weeks of age of layerss, the apparent digestibility of the dry matter of the feed, the excretion and retention of mineral matter, and the excretion of calcium and phosphorus, for bone quality, the Seedor index and the mineral matter and 
resistance to breaking the tibia. After analysis of variance, the data were submitted to regression analysis at the 5\% significance level. The apparent digestibility and the excretion of mineral matter worsened $(P<0.05)$ with the increase in the concentration of kaolin in the feed, since the retention of mineral matter behaved in a quadratic form, there was no significant difference $(P>0.05)$ in excretion of calcium and phosphorus. The seedor index increased linearly $(P<0.05)$, with no significant difference for the other bone parameters $(P>0.05)$. The inclusion of kaolin favored mineral retention and bone quality in laying hens at the end of the production cycle, without promoting changes in calcium and phosphorus retention and reduced feed digestibility.

Keywords: Clay; calcium; phosphorus; Seedor index; bone resistance. 


\section{INTRODUÇÃO}

O caulim é um dos aditivos que podem ser utilizados na nutrição animal. Ele é uma argila utilizada comumente como inerte em rações avícolas (Safaeikatouli et al., 2011). Devido a sua capacidade de fixar moléculas, ele pode ser consumido por todas as espécies animais, não sendo absorvido no trato gastrointestinal, porém pode se ligar às micotoxinas de modo a eliminá-las junto com as excretas do animal, impedindo que ocorra intoxicação (Compêndio Brasileiro de Nutrição Animal, 2017). Além do seu uso como aditivo tecnológico, quando utilizado em maiores concentrações pode atuar como aditivo zootécnico, equilibrando a microbiota quando promove melhor digestão e absorção dos nutrientes, consequentemente melhorando o desempenho das aves (Owen et al., 2012).

Świątkiewicz et al. (2010) estudaram poedeiras semipesadas em final de ciclo produtivo constataram que aditivos que atuam promovendo melhoria na saúde do trato gastrointestinal, tais como acidificantes e prebióticos, aumentaram a disponibilidade de cálcio e fósforo, devido a redução do $\mathrm{pH}$ intestinal, que gerou a um aumento da atividade digestiva das enzimas endógenas (conversão acelerada de pepsinogênio em pepsina) e na solubilidade dos minerais. Ustundag e Ozdogan (2018) também observaram maior absorção de minerais, refletindo inclusive em melhora na qualidade óssea quando incluíram essa classe de aditivos nas rações de aves.

O metabolismo do $\mathrm{Ca}$ e $\mathrm{P}$ é essencial para a homeostase do animal, segundo Rostagno et al. (2017), galinhas poedeiras semipesadas necessitam de alta demanda nutricional de cálcio que será direcionada para formar a casca do ovo, processo esse que está diretamente ligado ao metabolismo desse mineral. Apenas para a formação de um único ovo as galinhas necessitam de 2 à 2,5 gramas de cálcio (Olgun e Aygun, 2016).

Outro mineral de grande importância para a formação da casca do ovo é o fósforo, sendo que a exigência de $P$ disponível para as poedeiras leves e semipesadas é de 0,368 gramas/ave/dia (Rostagno et al., 2017). O P é utilizado para a deposição na gema do ovo e também se combina com o Ca para ser depositado no osso. Portanto com a mobilização de cálcio ósseo existe também uma liberação de fósforo na corrente sanguínea, sendo essa, suficiente para suprir as necessidades tanto metabólicas, quanto para a deposição na gema. Em caso de um excesso na liberação de fósforo, irá ocorrer uma menor liberação de cálcio e consequentemente uma pior formação da casca do ovo (Franco e Sakamoto, 2007; Magalhães, 2007).

A rigidez do tecido ósseo é resultante da deposição de cálcio e fósforo, na forma de hidroxiapatita, durante o processo de mineralização óssea. Esses dois minerais perfazem cerca de $70 \%$ da composição óssea, os $30 \%$ restantes são compostos de matéria orgânica, principalmente colágeno (Bruno, 2002), sendo a quantidade de cinzas nos ossos um bom parâmetro de qualidade óssea, devido à sua facilidade e praticidade de obtenção (Sanni, 2017).

Existem três tipos de tecido ósseo em galinhas poedeiras, incluindo 0 cortical, trabecular e osso medular, sendo este último, o local onde ocorre a deposição de $\mathrm{Ca}$ necessária para a formação de casca de ovo (Kim et al., 2012). O cálcio de origem dietética é extremamente importante, no entanto existe grande mobilização óssea de $\mathrm{Ca}$ particularmente durante períodos escuros, quando as galinhas não ingerem alimentos. 

semipesadas alimentadas com caulim no final do ciclo produtivo

Aproximadamente $30 \%$ das galinhas, sofrem com osteoporose ao longo do ciclo produtivo (Budgell e Silversides, 2004). Essa patogenia causa dor e limita os movimentos das aves, dificultando o consumo de ração e água, além de debilitar ossos longos, deixando-os mais frágeis e susceptíveis a fraturas. Essa doença é predominante principalmente em aves mais velhas, visto que as mesmas reduzem sua atividade metabólica com o avançar da idade, reduzindo a absorção de nutrientes, entre eles os minerais cálcio e fósforo, além disso, a quantidade que vitamina $D$ produzida pela ave também reduz, dificultando ainda mais a absorção desses minerais no intestino. Em contrapartida, com o avanço genético das empresas de linhagem a cada geração temos galinhas mais produtivas, passando maior tempo dentro do sistema de produção, consequentemente maior a tendência de aparecimento de problemas ósseos (Olgun e Aygun, 2016).

A incorporação de argilas, tais como caulim, bentonita e zeólitas, objetivando melhorias na qualidade óssea demonstraram resultados satisfatórios na produção de aves. A inclusão de até $3 \%$ de diferentes argilas (as mesmas suprecitadas), promoveu melhora nas características morfométricas de tíbias de frangos de corte de 42 dias de idade, representada por ossos mais densos e maior conteúdo minetal na tíbia (Safaeikatouli et al., 2012). A inclusão de zeólitas nas rações de galinhas poedeiras, também tem sido associada ao aumento dos níveis de $\mathrm{Ca}, \mathrm{P}$ e $\mathrm{Mg}$ nos ossos (Herzig et al. 2008). Tais melhorias na qualidade óssea foram atribuídas à redução da taxa de passagem da digesta provocada pela inclusão das argilas, permitindo maior digestão e absorção, assim como a propriedade de troca catiônica dos mesmos com $\mathrm{Ca}$ e $\mathrm{P}$, possibilitando com que esses minerais sejam absorvidos pelas aves em maior quantidade (Safaeikatouli et al., 2012).

De forma antagônica alguns autores observaram que inclusão de argilas na ração interferiu na absorção de cálcio (Zimmermann, 2014) e de fósforo (Zimmermann, 2014; Schneider et al., 2017). A adsorção de fosfato pela bentonita já foi comprovada em soluções aquosas, onde ocorreu remoção de fósforo contaminante (Pawar et al., 2016), devido a afinidade dessa argila por substâncias polares (Pasha et al., 2008). Presume-se, portanto, que a bentonita adsorve o fosfato em nível intestinal, provocando a redução de sua concentração sérica (Schneider et al., 2019).

Diante deste contexto, objetivou-se estudar a qualidade óssea, a excreção mineral e a digestibilidade de matéria de seca de poedeiras semipesadas alimentadas com rações contendo diferentes níveis de caulim.

\section{MATERIAL E MÉTODOS}

O estudo experimental foi realizado no galpão do Setor Experimental de Avicultura da Universidade Federal Rural do Rio de Janeiro (UFRRJ) localizado em Seropédica - RJ. Foram alojadas 144 galinhas semipesadas, da linhagem Dekalb Brown, ainda na fase de recria (14 semanas), em sistema piramidal de gaiolas de produção, compostas de bebedouro tipo nipple e comedouro tipo calha.

As aves foram distribuídas em delineamento inteiramente casualizado, com seis tratamentos, de seis repetições, contendo quatro aves por repetição. A partir de 63 semanas de idade iniciou-se o fornecimento das rações experimentais, que se diferenciavam pela inclusão de níveis crescentes de caulim. 
$\mathrm{O}$ aditivo foi cedido pela empresa $\mathrm{CaO}$ do Brasil Ltda, apresentando composição tabelada de $21,90 \%$ de $\mathrm{Al}_{2} \mathrm{O}_{2}, \quad 62,80 \%$ de $\mathrm{SiO}_{2} ; 1,40 \%$ de $\mathrm{Fe}_{2} \mathrm{O}_{3} ; 0,40 \%$ de $\mathrm{CaO}$, sendo que o mesmo foi analisado, para esse estudo, obtendo-se $93,6 \%$ de matéria mineral, destas $0,08 \%$ de fósforo e $0,28 \%$ de cálcio. Os tratamentos foram: Controle (sem a inclusão do aditivo); e inclusão de 1, 2, 3, 4 e $5 \%$ de caulim na dieta.

As dietas experimentais foram isoproteicas e isoenergéticas, formuladas a base de milho e farelo de soja, atendendo aos níveis estabelecidos por Rostagno et al. (2011).

Tabela 1 - Composição das rações de poedeiras semipesadas contendo diferentes níveis de caulim para durante o período experimental.

\begin{tabular}{|c|c|c|c|c|c|c|}
\hline \multirow{2}{*}{ Ingredientes (\%) } & \multicolumn{6}{|c|}{ Níveis de caulim (\%) } \\
\hline & 0 & 1 & 2 & 3 & 4 & 5 \\
\hline Milho (7,88\% PB) & 66,615 & 64,481 & 62,362 & 60,243 & 58,228 & 56,008 \\
\hline Farelo de soja (45\% PB) & 21,470 & 21,883 & 22,280 & 22,675 & 22,947 & 23,465 \\
\hline Óleo de soja & 0,854 & 1,578 & 2,297 & 3,017 & 3,706 & 4,455 \\
\hline Sal comum & 0,445 & 0,446 & 0,447 & 0,448 & 0,449 & 0,449 \\
\hline Calcário calcítico & 9,164 & 9,160 & 9,154 & 9,149 & 9,144 & 9,139 \\
\hline Fosfato bicálcico & 0,978 & 0,983 & 0,988 & 0,993 & 0,999 & 1,003 \\
\hline Suplemento vitaminico ${ }^{1}$ & 0,120 & 0,120 & 0,120 & 0,120 & 0,120 & 0,120 \\
\hline Suplemento mineral ${ }^{2}$ & 0,120 & 0,120 & 0,120 & 0,120 & 0,120 & 0,120 \\
\hline DL-Metionina (99\%) & 0,175 & 0,177 & 0,180 & 0,183 & 0,187 & 0,189 \\
\hline L-Lisina HCL (78\%) & 0,007 & 0 & 0 & 0 & 0,047 & 0 \\
\hline L-Treonina & 0,005 & 0,005 & 0,005 & 0,005 & 0,006 & 0,005 \\
\hline Cloreto de colina $(60 \%)$ & 0,037 & 0,037 & 0,037 & 0,037 & 0,037 & 0,037 \\
\hline BHT & 0,010 & 0,010 & 0,010 & 0,010 & 0,010 & 0,010 \\
\hline Caulim & 0 & 1 & 2 & 3 & 4 & 5 \\
\hline Total & 100 & 100 & 100 & 100 & 100 & 100 \\
\hline \multicolumn{7}{|c|}{ Composição nutricional calculada } \\
\hline $\begin{array}{ll}\text { Energia } & \text { metabolizável } \\
(\text { Mcal/Kg) } & \end{array}$ & 2,850 & 2,850 & 2,850 & 2,850 & 2,850 & 2,850 \\
\hline Proteína Bruta (PB\%) & 15,6 & 15,6 & 15,6 & 15,6 & 15,6 & 15,6 \\
\hline Cálcio $(\mathrm{Ca} \%)$ & 3,850 & 3,850 & 3,850 & 3,850 & 3,850 & 3,850 \\
\hline Fósforo disponível (Pd\%) & 0,275 & 0,275 & 0,275 & 0,275 & 0,275 & 0,275 \\
\hline Cloro $(\%)$ & 0,300 & 0,300 & 0,300 & 0,299 & 0,299 & 0,298 \\
\hline Sódio (\%) & 0,211 & 0,211 & 0,211 & 0,211 & 0,211 & 0,211 \\
\hline Potássio (\%) & 0,595 & 0,596 & 0,597 & 0,598 & 0,597 & 0,600 \\
\hline Lisina dig (\%) & 0,684 & 0,685 & 0,690 & 0,696 & 0,735 & 0,707 \\
\hline Lisina Total (\%) & 0,769 & 0,770 & 0,775 & 0,781 & 0,820 & 0,792 \\
\hline Met + Cistdig. (\%) & 0,628 & 0,628 & 0,629 & 0,629 & 0,630 & 0,630 \\
\hline Met + Cist total $(\%)$ & 0,692 & 0,692 & 0,692 & 0,692 & 0,692 & 0,692 \\
\hline Metionina dig (\%) & 0,403 & 0,404 & 0,406 & 0,408 & 0,411 & 0,412 \\
\hline Metionina total (\%) & 0,426 & 0,427 & 0,429 & 0,431 & 0,433 & 0,435 \\
\hline
\end{tabular}


A coleta total das excretas, para avaliação da digestibilidade aparente da matéria seca e excreção mineral, foi realizada quando as aves atingiram 85 semanas de idade, de modo que foram colocadas bandejas envelopadas com plástico, uma embaixo de cada gaiola (Sibbald e Slinger, 1963). As coletas foram realizadas duas vezes ao dia, às oito e às dezessete horas, por três dias consecutivos (Sakomura e Rostagno, 2016). As excretas de cada gaiola foram pesadas imediatamente após cada coleta e acondicionadas em sacos plásticos devidamente identificados e armazenados em freezer $\left(-10^{\circ} \mathrm{C}\right)$ para análises posteriores. A ração consumida foi calculada com base na quantidade pesada previamente para todo o ensaio de metabolismo para cada parcela, subtraindo as sobras.

A digestibilidade aparente da matéria seca (Digap) foi considerada como, a quantidade percentual de matéria seca excretada em relação à matéria seca consumida, conforme equação descrita abaixo:

$\operatorname{Dig}_{\text {ap }}(\%)=[1-($ MS excretada - MS consumida $)] \times 100$

As excretas foram pré-secas em estufa ventilada a $55^{\circ} \mathrm{C}$ por 72 horas, foram moídas em moinho de facas com peneira de malha de $1 \mathrm{~mm}$ de malha e armazenadas em vasilhames hermeticamente fechados. As rações e as excretas foram analisadas para matéria seca, através de secagem em estufa à $105^{\circ} \mathrm{C}$ por 16 horas, e matéria mineral, em forno tipo mufla a $580^{\circ} \mathrm{C}$ durante quatro horas (Detmann et al., 2012). Os coeficientes de retenção da matéria mineral foram considerados, como a quantidade percentual de matéria mineral excretada em relação à matéria mineral consumida, conforme equação descrita anteriormente. Através da técnica de colorimetria, procedeu-se a determinação dos teores de fósforo das excretas (Detmann et al., 2012) e os de cálcio, por absorção atômica (Zenebon et al., 2008).

A avaliação da qualidade óssea foi realizada em tíbias direitas de 48 aves eutanasiadas para obtenção do índice Seedor, resistência a quebra da tíbia e matéria mineral.

Para a realização da desossa, os ossos foram devidamente identificados e mergulhados em água fervente por 10 minutos, posteriormente foram desossados com auxílio de bisturi e tesouras de modo a retirar todo o material aderido ao osso (Bruno, 2002). Utilizando este método de desossa é possível extrair cerca de $80 \%$ da gordura presente no osso (Almeida Paz et al., 2009).

Nos ossos in natura, procedeu-se posteriormente a esse procedimento, a determinação do índice Seedor, medindo os ossos em seu maior comprimento das epífises, com o auxílio de um paquímetro, e aferindo o seu peso com o auxilio de uma balança semi-analítica digital. Após, dividiu-se o peso da tíbia $(\mathrm{mg})$ por seu comprimento ( $\mathrm{mm}), \quad$ segundo metodologia desenvolvida por Seedor et al. (1991).

A resistência a quebra da tíbia, foi realizada em texturômetro, Stable Micro Systems Texture Analysers modelo TA.XT plus, conectado a um computador (para transmissão dos dados), calibrado com velocidade préteste: $2,0 \mathrm{~mm} / \mathrm{s}$; velocidade do teste: 1,0 $\mathrm{mm} / \mathrm{s}$ e velocidade pós-teste: $4,0 \mathrm{~mm} / \mathrm{s}$. As tíbias foram acomodadas e centralizadas em suporte adaptado para este teste com vão livre de $6 \mathrm{~cm}$ e $7 \mathrm{~mm}$ de distância da sonda. Um software específico foi utilizado para registrar a força necessária empregada para o rompimento total dos ossos em quilograma-força (Kgf) (Faitarone et al. 2012).

A matéria mineral com base na matéria seca e na matéria natural dos 
ossos, foi mensurada após pesagem dos mesmos em balança analítica digital e colocados em estufa de esterilização a $105^{\circ} \mathrm{C}$, por 16 horas, e após esfriarem em dessecador, foram pesados novamente, obtendo-se então, a diferença entre o peso correspondente ao teor de matéria seca desengordurada (\%), conforme metodologia descrita por Kim et al. (2004). Para obtenção da matéria mineral (cinzas), dois gramas das amostras foram moídas, pesadas e colocadas na mufla a $600^{\circ} \mathrm{C}$ por 4 horas.

Os resultados foram submetidos à análise de variância utilizando-se o Programa BioEstat ${ }^{\circledR}$. Posteriormente, os efeitos dos níveis de caulim foram estimados por meio de análise das variáveis pelos modelos de regressão linear e quadrática ao nível de significância de $5 \%$, conforme o melhor ajustamento obtido para cada variável, baseado no maior valor de coeficiente de determinação para a escolha do modelo.

\section{RESULTADOS E DISCUSSÃO}

A digestibilidade aparente da matéria seca foi reduzida de forma linear $(P<0,05)$ com a inclusão de níveis crescentes de caulim (Tabela 2). O caulim é um ingrediente inerte de muito baixa digestão, dessa forma, as rações que receberam maiores inclusões da argila, tiveram menores inclusões de ingredientes de alta digestibilidade (como o milho, por exemplo), portanto a digestibilidade de toda a dieta foi reduzida à medida que se elevaram os níveis de inclusão do caulim. Além desse fato, de acordo com Subramaniam e Kim (2015), as argilas possuem a propriedade de formarem coloides com a água, o que torna a digesta mais viscosa dificultando a atuação das enzimas digestivas, e assim reduzindo a ação das enzimas digestivas, resultando portanto em menor digestão e absorção dos nutrientes.

Tabela 2. Digestibilidade aparente da matéria seca (Digap), matéria mineral (MM), coeficiente de retenção de matéria mineral ( $\mathrm{MM}$ ret) e níveis de fósforo ( $P$ excretas) e cálcio (Ca excretas) das excretas de galinhas poedeiras semipesadas alimentadas com diferentes níveis de caulim na ração.

\begin{tabular}{|c|c|c|c|c|c|c|c|c|}
\hline \multicolumn{9}{|c|}{ Níveis de caulim (\%) } \\
\hline & 0 & 1 & 2 & 3 & 4 & 5 & Regressão & $C V^{1}$ \\
\hline $\operatorname{Dig}_{a p}(\%)$ & 77,13 & 78,39 & 77,60 & 73,73 & 74,21 & 73,30 & $\mathrm{~L}^{2}$ & 3,72 \\
\hline $\mathrm{MM}(\mathrm{g})$ & 0,093 & 0,079 & 0,109 & 0,111 & 0,120 & 0,138 & $\mathrm{~L}^{3}$ & 21,94 \\
\hline MM ret $(\%)$ & 21,97 & 50,21 & 39,93 & 44,42 & 33,896 & 41,02 & $Q^{4}$ & 30,91 \\
\hline P excretas (\%) & 1,681 & 1,971 & 1,578 & 1,490 & 1,4285 & 1,367 & $N S^{5}$ & 14,88 \\
\hline Ca excretas (\%) & 1,916 & 2,303 & 2,322 & 3,289 & 1,809 & 2,511 & $N S^{5}$ & 31,85 \\
\hline
\end{tabular}

${ }^{1} \mathrm{CV}=$ coeficiente de variação; ${ }^{2} \mathrm{~L}=$ Efeito de regressão linear, $\mathrm{Y}=78,2685-1,0162 \mathrm{X}, \mathrm{P}=0,001 ;{ }^{3} \mathrm{~L}=\mathrm{Efeito}$ de regressão linear, $Y=0,0836+0,0099 X, P<0,001 ;{ }^{4} Q=$ Efeito de regressão quadrático, $Y=28,6420+10,9638 X-$ $1,9025 X^{2}, P=0,0211 ;{ }^{5} \mathrm{NS}=$ não significativo

Esses resultados corroboram os encontrados com Poulsen e Oksbjerg (1995) que também relataram efeitos negativos sobre a digestibilidade da matéria seca com a adição de $3 \%$ de clinoptilolita em suínos na fase de crescimento. Lowndeset al.(2019), forneceram zeólitas para cães ( 0 à 0,5 $\%$ de inclusão), também observaram redução linear do coeficiente de digestibilidade da matéria seca. No entanto, Yalçin et al. (2017) constataram que houve maior digestibilidade précecal da matéria seca em frangos de 
corte alimentados com rações contendo $1 \%$ de sepiolita, não havendo diferença significativa entre aves que receberam $2 \%$ e que não receberam a argila. Li e Kim (2013) relataram que a suplementação dietética com 0,5 e 1,0\% da argila sericita aumentou a digestibilidade da matéria seca em 3,9 e $7,5 \%$ em suínos.

Wang et al. (2012) utilizando suínos desafiados com a micotoxina zearalenona, observaram que ao incluir $2 \%$ da argila montmorillonita ocorreu melhoria na digestibilidade da dieta controle (sem a toxina).

Resultados opostos aos do presente estudo foram descritos por Gonzales et al. (1996), que obtiveram aumento da digestibilidade aparente da ração de $82 \%$ para $88 \%$, acrescentando $5 \%$ de zeólitas em dietas destinadas a frangos, e Safaeikatouli et al. (2012) avaliando a digestibilidade de frangos de corte incluindo caulim, bentonita e zeólita em rações, nos níveis de 0, 1,5 e $3 \%$, verificaram maior digetibilidade précecal em rações contendo caulim ou zeólitas, ambos ao nível de $3 \%$.

A excreção de matéria mineral, também se comportou de forma linear $(Y=0,0836+0,0099 X)$, visto que, à medida que foram incluídos maiores níveis de caulim nas rações, a excreção de minerais também aumentou. A composição de $93,63 \%$ de matéria mineral da argila utilizada no presente experimento pode explicar esse comportamento linear, ou seja, essa alta concentração de matéria mineral característica do tipo de caulim utilizado, quando agregada às rações das aves que receberam os maiores níveis, por estar complexada na argila, não seria digerida nem absorvida mais por fim, excretada. Incluindo uma argila comercial Ferreira et al. (2005) também encontraram maior excreção de matéria mineral em frangos, justificando esse fato pela quantidade de minerais presentes no silicato de alumínio.
O coeficiente de retenção de matéria mineral se comportou de maneira quadrática $\left(Y=28,6420+10,9638 X-1,9025 X^{2}\right)$

aumentando até o nível de inclusão de $2,88 \%$ de caulim e reduzindo posteriormente com a inclusão de níveis maiores. Apesar do efeito quadrático, a redução na retenção da matéria mineral com a elevação dos níveis de caulim, não comprometeu a qualidade óssea, que inclusive, melhorou comprovado pelos resultados obtidos para o Índice de Seedor (Tabela 3). Conforme descrito por Subramaniam e Kim (2015), a presença de argilas no trato gastrointestinal promove maior ativação de enzimas pancreáticas que por sua vez, essa redução do $\mathrm{pH}$ poderia clivar em maior quantidade os minerais presentes nos ingredientes da ração aumentado assim, a absorção e retenção dos mesmos. Ainda, segundo os autores, com a elevação dos níveis do caulim na dieta, pode ter ocorrido uma maior da viscosidade da digesta, limitando o aumento da retenção de minerais.

A melhoria da qualidade óssea é fundamental, sobretudo ao final do ciclo produtivo, momento em que as aves apresentam maior desgaste fisiológico, reduzindo a digestão e absorção de minerais, refletindo em maior debilidade óssea Budgell e Silversides (2004). Safaeikatouli et al. (2012) não encontraram diferenças significativas para excreção de minerais utilizando até $3 \%$ de caulim em rações de frangos de corte em comparação ao controle.

A concentração de fósforo e cálcio excretado pelas galinhas, não foram alterados pela inclusão de caulim nas rações $(P>0,05)$. As argilas permitem trocas catiônicas com os substratos podendo se ligar aos íons de cálcio e fósforo da digesta formando sais insolúveis (Schneider et al., 2017) e reduzindo a sua absorção. O processo de adsorção está fortemente 

semipesadas alimentadas com caulim no final do ciclo produtivo

relacionado à distribuição de carga, dimensões dos poros e área de superfície acessível do adsorvente, bem como à polaridade, solubilidade estrutural e características físicoquímicas (Trckova et al., 2004).

Portanto, dependendo da sua mineralogia ou granulometria, as argilas funcionam de forma diferente, podendo atuar de forma benéfica (ajudando na absorção do mineral) ou deletéria (se complexando com o mesmo e tornando$\mathrm{o}$ indisponível).

A possibilidade da argila se ligar com minerais tornando-os indisponíveis não foi confirmada por Khanedar et al. (2012), utilizando bentonitas. Safaeikatouli et al. (2012), utilizando caulim, em rações de frangos de corte e Durak et al. (2017), incluindo zeólitas para codornas japonesas, não encontraram alterações na concentração de $\mathrm{Ca}$ e $\mathrm{P}$ no sangue dessas aves, independente do nível de argila na ração.

Li e Kim (2013) relataram que a suplementação dietética da argila sericita aumentou a retenção do cálcio e do fósforo em 5,0 e $19,1 \%$, respectivamente, quando suínos foram alimentados com dietas contendo 0,5 ou $1,0 \%$ dessa argila. Também com suínos, Chen et al. (2005) relataram que a retenção do cálcio foi elevada pela adição de $0,5 \%$ de uma argila comercial na dieta, enquanto a matéria seca e a retenção do fósforo não foram afetados. Souza et al. (2019), fornecendo 0; 1,5; 3,0 e $4,5 \%$ de caulim nas rações de codornas de postura observaram que com a maior inclusão da argila, menor foi a excreção de cálcio. Fornecendo zeólitas à frangos de corte, Bintaş et al. (2014) observaram maior excreção de cinzas e cálcio, não sendo significativo para o fósforo.

Resultados opostos ao presente estudo, foram encontrados por Macháček et al. (2010), em que os mesmos constataram redução na retenção de matéria mineral, Ca e $P$, em poedeiras alimentadas com a inclusão de $2 \%$ de zeólita, entretanto com 0 aumento da incorporação da argila na ração para $4 \%$, a retenção desses minerais foi aumentada.

Yalçin et al. (2017) incluíram 0\%, $1 \%$ e $2 \%$ de sepiolita na ração de frangos de corte, também não observaram maior digestibilidade de cálcio e fósforo, não havendo diferenças significativas também para os mesmos minerais no sangue, assim como Attar et al. (2019), que não constataram diferença significativa na retenção de $\mathrm{Ca}$ em frangos de 11 à 24 dias de idade, fornecendo níveis de $0 ; 0,75$ e $1,5 \%$ de bentonita em rações peletizadas, ocorrendo no entanto maior retenção de $\mathrm{P}$ com o nível de inclusão mais alto.

Tabela 3 - Características das tíbias de galinhas semipesadas às 85 semanas de idadde alimentadas com diferentes níveis de caulim na ração no final do ciclo produtivo.

\begin{tabular}{|c|c|c|c|c|c|c|c|c|}
\hline \multicolumn{9}{|c|}{ Níveis de caulim (\%) } \\
\hline & 0 & 1 & 2 & 3 & 4 & 5 & Regressão & $\mathrm{CV}^{1}$ \\
\hline Índice de Seedor & 80,16 & 86,09 & 88,46 & 86,95 & 87,67 & 92,56 & $\mathrm{~L}^{2}$ & 8,66 \\
\hline $\mathrm{RQ}^{4}$ & 13,372 & 13,716 & 13,553 & 15,494 & 13,263 & 13,945 & $\mathrm{NS}^{3}$ & 17,94 \\
\hline$\% \mathrm{MS}$ & 86,23 & 83,34 & 82,39 & 80,01 & 83,80 & 81,54 & $\mathrm{NS}^{3}$ & 5,63 \\
\hline$\% M M$ na $\mathrm{MN}$ & 39,06 & 38,06 & 41,77 & 38,26 & 39,49 & 38,48 & $\mathrm{NS}^{3}$ & 8,84 \\
\hline$\% M M$ na MS & 45,36 & 45,65 & 51,01 & 47,86 & 47,03 & 47,28 & $\mathrm{NS}^{3}$ & 8,61 \\
\hline
\end{tabular}


O índice de Seedor foi influenciado de modo linear $(P<0,05)$, demonstrando melhoria na qualidade óssea através da mensuração por esse parâmetro, à medida que se incluía maiores concentrações de caulim nas rações. 0 índice de Seedor correlaciona o tamanho e o peso do osso e indica indiretamente a maior densidade óssea, quanto maior for o seu valor. Segundo Olgun e Aygun (2016) aditivos que beneficiem a saúde intestinal, como é o caso do caulim, quando incluídos na ração de galinhas poedeiras podem promover maior absorção de nutrientes, melhorando a qualidade óssea. Galinhas mais velhas possuem menores taxas de digestão e absorção de nutrientes, entre eles os minerais, apresentando maior probabilidade de ocorrência de transtornos ósseos. Esse fato não ocorreu no presente estudo, apesar da retenção da matéria mineral se comportar de maneira quadrática com a elevação dos níveis de caulim (Tabela 2), e comprovada também pela ausência de alterações nas concentrações de cálcio e de fósforo (que são os principais minerais componentes dos ossos) nas excretas, indicando que a absorção desses elementos se manteve em concentrações adequadas para a manutenção da qualidade óssea (Ammerman, et al. 1995). Portanto, o aumento linear do índice de Seedor, pode indicar maior participação de outros minerais que não foram avaliados, os quais de acordo com (Olgun e Aygun, 2016), também desempenham importantes funções no crescimento e massa das tíbias, tais como os microminerais (zinco, manganês, boro e cobre).

A RG óssea assim como a porcentagem de matéria seca e concentrações de matéria mineral na matéria seca e na matéria natural das tíbias das poedeiras não foram afetadas $(P>0,05)$ com a inclusão de níveis crescentes de caulim na ração (Tabela
3). A rigidez do tecido ósseo é resultante da deposição de cálcio e fósforo, na forma de hidroxiapatita, durante o processo de mineralização óssea. Nos ossos, estão presentes cerca de 99\% do cálcio (Olgun e Aygun, 2016) e $80 \%$ do fósforo (De Groote e Huyghebaret, 1997) e o aumento da mineralização óssea está associado a um aumento da força da mesma (Shim et al., 2012).

Rowland et al. (1967) examinaram a relação entre a resistência à quebra óssea e o conteúdo dietético de cálcio e fósforo e encontraram um coeficiente de correlação de 0,98 entre a cinza tibial média e a força média de ruptura óssea, levando os autores a concluir que a resistência óssea era tão boa quanto a cinza tibial para avaliação de qualidade óssea. No entanto, a resistência à quebra relaciona-se também com as às concentrações de proteínas colagenosas e não colagenosas, e não só com os minerais no osso (Araújo et al., 2011). Esse resultado já foi confirmado por outros autores, que verificaram que maiores teores de cinzas ósseas e fósforo nas tíbias de frangos de corte em fase de crescimento não resultaram em maior resistência à quebra (Runho et al., 2001), devendo a desmineralização óssea ser prolongada para induzir a perda de resistência à quebra.

No presente experimento, a inclusão de caulim não propiciou redução da excreção de cálcio e fósforo da dieta, no entanto, possibilitou maior retenção de minerais até 2,88\% (Tabela 2 ), sem contudo, promover reflexo na concentração de matéria mineral dos ossos (Tabela 3) que é diretamente afetada pela mobilização óssea de cálcio particularmente durante a noite, quando as galinhas não ingerem alimentos (Kim et al., 2012) e é o período mais ativo de formação da casca.

Corroborando o presente estudo, Herzig et al. (2008), utilizando 
poedeiras, e Eleroğlu et al. (2011) e Khanedar et al. (2012), trabalhando com frangos de corte até os 42 dias, não observaram diferenças significativas sobre a quantidade de matéria mineral na tíbia quando adicionaram argilas nas rações. As características morfométricas das tíbias também não sofreram alterações pelo uso das argilas segundo Eleroğlu et al. (2011). Berto et al. (2013) utilizando poedeiras semipesadas de 67 semanas de idade, não encontraram efeitos significativos para resistência à quebra e porcentagem de cinzas quando adicionaram até $0,5 \%$ de zeólitas nas rações.

Papaioannou et al. (2005), concluíram que a inclusão de argilas pode melhorar a resistência à quebra da tíbia e frangos, e a concentração de matéria mineral na mesma, no entanto esse fato é dependente da quantidade de inclusão do cálcio dietético. Bintaş et al. (2014) obtiveram melhor peso relativo da tíbia em frangos, quando adicionaram zeólitas em dietas deficientes em cálcio, e a inclusão da argila aumentou também a quantidade de cinzas na tíbia independente do nível de cálcio da ração, entretanto quando fornecida uma ração com níveis ideais de cálcio, acrescidos de zeólitas os piores valores foram observados para o peso do osso. Não houve diferenças entre o comprimento desses ossos e a força de cisalhamento.

Safaeikatouli et al. (2012), incluindo 1,5 ou $3 \%$ de diferentes argilas (caulim, bentonitas ou zeólitas), observaram maior resistência à quebra quando adicionados $3 \%$ de caulim na ração de frangos em comparação ao controle, também observando, que a inclusão de caulim (independente do nível utilizado) não propiciou maior índice de Seedor. Assim como Schneider et al. (2019), estudando a adição de bentonitas em rações de frangos de corte de 14 a 21 dias de idade, observaram redução na matéria mineral (\%) na tíbia com a inclusão de
$0,50 \%$ da argila, não observando diferença significativa para o índice de seedor, ambos estudo contrapõem o presente experimento. Yalçin et al. (2017) suplementando frangos de corte com 0 à $2 \%$ de sepiolita, não encontram efeitos significativos para características morfométricas das tíbias (comprimento e espessura), assim como para resistência à quebra e os teores de matéria mineral. Khanedar et al.(2012), não encontraram diferenças nas cinzas $(45,8 \%)$ das tíbias de frangos suplementadas com até $1,5 \%$ de bentonita na dieta.

\section{CONCLUSÕES}

A inclusão de até $2,88 \%$ de caulim nas dietas experimentais de galinhas poedeiras semipesadas de 85 semanas de idade aumentou retenção de minerais. Houve melhora linear da qualidade óssea com nível de até $5 \%$, justificando a importância zootécnica da utilização da argila, sendo uma estratégia nutricional interessante, para essa categoria no final do ciclo produtivo. Apesar da redução da digestibilidade da dieta e da elevação da excreção mineral, não houve, contudo, alteração na retenção do cálcio e do fósforo, que são fundamentais para a formação dos ossos e dos ovos, e consequentemente no desempenho produtivo das aves.

\section{AGRADECIMENTOS}

A empresa $\mathrm{CaO}$ do Brasil Ltda. por fornecer $o$ ingrediente testado e apoio financeiro a este projeto. $O$ presente trabalho foi realizado com apoio da Coordenação de Aperfeiçoamento de Pessoal de Nível Superior - Brasil (CAPES) - Código de Financiamento 001.

\section{NOTAS INFORMATIVAS}


Esse trabalho foi aprovado pela Comissão de Ética do Uso de Animais em Experimentos Científicos, sob o número de processo: 23083.005984/2017-02.

\section{REFERÊNCIAS}

ALMEIDA PAZ, I. C. L.; MENDES, A. A.; BALOG, A.; et al. Efeito do cálcio na qualidade óssea e de ovos de poedeiras. Archivos de Zootecnia, v. 58, n. 222, p. 173-183, 2009.

AMMERMAN, C. B.; BAKER, D. H.; LEWIS, A. J. Bioavallability of nutrients for animais: amino acids, minerals, and vitamins. San Diego: Acadenic Press, 1995. 441p.

ARAÚJO, G. M.; VIEITES, F. M.; BARBOSA, A. A.; et al. Variação aniônica da dieta sobre características ósseas de frangos de corte: resistência à quebra, composição orgânica e mineral. Arquivo Brasileiro de Medicina Veterinária e Zootecnia, v.63, p.954-961, 2011.

ATTAR, A., KERMANSHAHI, H., GOLIAN, A., et al. Conditioning time and sodium bentonite affect pellet quality, growth performance, nutrient retention and intestinal morphology of growing broiler chickens.. British Poultry Science, v. 60, n. 6, p. 777-783, 2019.

BERTO, D. A.; GARCIA, E. A.; PELÍCIA, $\mathrm{K}$; ; et al. Effects of dietary clinoptilolite and calcium levels on the performance and egg quality of commercial layers. Revista Brasileira de Ciência Avícola, v. 15, n. 3, p. 263-268, 2013.

BINTAŞ, E.; BOZKURT, M.; KÜÇÜKYILMAZ, K.; et al. Efficacy of supplemental natural zeolite in broiler chickens subjected to dietary calcium deficiency. Italian Journa Iof Animal Science, v. 13, n. 2, p. 3141, 2014.

BRUNO, L. G. D. Desenvolvimento ósseo em frangos de corte: Influência da restrição alimentar e da temperatura

ambiente.

2002. Jaboticabal, 72 f. Tese (Doutorado em Zootecnia) - Faculdade de Ciências Agrárias e Veterinárias, Universidade Estadual de Paulista - UNESP.

BUDGELL, K. L.; SILVERSIDES, F. G. Bone breakage in three strains of endof-lay hens. Canadian Journal of Animal Science, v. 84, n. 4, p. 745-747, 2004.

CHEN Y. J.; KWON O. S.; MIN B.; et al. The effects of dietary Biotite $V$ supplementation as an alternative substance to antibiotics in growing pigs. Asian-Australasian Journal of Animal Sciences, v. 18, n. 11, p. 1642-1645, 2005.

OWEN, O. J.; NODU, M. B.; DIKE, U. A.; et al. The effects of dietary kaolin (clay) as feed additive on the growth performance of broiler chickens. Greener Journal of Agricultural Sciences, v. 2, n. 6, p. 233-236, 2012.

COMPÊNDIO BRASILEIRO DE ALIMENTAÇÃO ANIMAL. São Paulo: Sindirações/Anfal.

Campinas

CBNA/SDR/MA. 2017. 371p.

DE GROOTE, G.; HUYGHEBAERT, G. The bio-availability of phosphorus from feed phosphates for broilers as influenced by bio-assay method, dietary Ca-level and feed form. Animal Feed Science and Technology, v. 69, n. 4, p. 329-340, 1997.

DETMANN, E.; SOUZA, M.A. de; VALADARES FILHO, S. de C.; QUEIROZ, A.C. de; et al. Métodos para análise de alimentos. Visconde do Rio Branco: Ed Suprema, 2012. 214p.

DURAK, M. H.; BAYRIL, T.; ŞIMŞEK, A.; et al. Diyetsel Zeolitin, Japon Bıldırcınlarında Besi Performansı ve Bazı Biyokimyasal Parametreler Üzerine Etkisi. Harran Üniversitesi Veteriner Fakültesi Dergisi, v. 6, n. 1, p. 1-5, 2017.

ELEROĞLU, H.; YALÇIN, H.; YILDIRIM, A.. Dietary effects of Ca-zeolite 
supplementation on some blood and tibial bone characteristics of broilers. South African Journal of Animal Science, v. 41, n. 4, p. 319-330, 2011.

FAITARONE, A.B.G.; GARCIA, E.A.; ARTONI, S.M.B.; et al. Qualidade óssea de poedeiras comerciais leves alimentadas com rações suplementadas com diferentes óleos vegetais. Veterinária e Zootecnia, p. 356-365, 2012.

FERREIRA, A. C. K.; ALFARO, D. M.; SILVA, L. C. C.; et al. O uso de aluminossilicato (SilvetÒ) como adjuvante na melhora do aspecto das fezes e desempenho das aves. Archives of Veterinary Science, v.10, n.1, p.117-122, 2005.

FRANCO, J. R. G.; SAKAMOTO, M. I. Qualidade dos ovos: uma visão geral dos fatores que a influenciam, 2007. Revista AveWorld. Disponível em:http://www.aveworld.com.br/index.ph p?documento $=102$.

GONZALES, L. M.; VALDIVIE, M. E.; LONN-WO, E. Sacharine and Zeolite in Broiler Feeding. Cuba Journal of Agriculture Science, v.30, p.309-313, 1996.

HERZIG, I.; STRAKOVA, E.; SUCHY, P. Long-term application of clinoptilolite via the feed of layers and its impact on the chemical composition of long bones of pelvic limb (femur and tibiotarsus) and eggshell. Veterinarni Medicina, v. 53, p. 550-554, 2008.

KHANEDAR, F.; VAKILI, R.; ZAKIZADEH, S. Effects of two kinds of bentonite on the performance, blood biochemical parameters, carcass characteristics and tibia ash of broiler chicks. Global Vet, v. 9, n. 6, p. 720725. 2012.

KIM, W. K.; DONALSON, L.M.; HERRERA, P. et al. Effects of diferente bone preparation methods (fresh, dry, and fat-freedry) on bone parameters and the correlations between bone breaking strength and the other boneparameters. Poultry Science, v. 83 , n. 10, p. 16631666, 2004.

KIM, J. S.; JO, J. K.; YOON, S. Y.; et al. Effects of Kaolin (Natural Ligneous Clay) Supplementation on Performance and Egg Quality in Laying Hens. Journal of Animal Science and Technology, v. 53, n. 2, p. 133-138, 2011.

KIM, W. K.; BLOOMFIELD, S. A.; SUGIYAMA, T.; et al. Concepts and methods for understanding bone metabolism in laying hens.. World's Poultry Science Journal, v. 68, n. 1, p. 71-82, 2012.

LI, J.; KIM, I. H. Effects of dietary supplementation of sericite on growth performance, nutrient digestibility, blood profiles and fecal microflora shedding in growing pigs. Animal feed science and technology, v. 184 , n. $1-4$, p. 100-104, 2013.

LOWNDES, F. G., SABCHUK, T. T., RISOLIA, L.W., et al. Zeolite inclusion in dog extruded diets: digestibility, fecal characteristics, and palatability.Semina: Ciências Agrárias, v. 40, n. 6, p. 26732682, 2019

MACHÁČEK, M.; VEČEREK, V.; MAS, $\mathrm{N}$.; et al. Effect of the feed additive clinoptilolite (ZeoFeed) on nutrient metabolism and production performance of laying hens. Acta Veterinaria Brno, v. 79, n. 9 , p. 29-34, 2010.

MAGALHÃES, A. P. C. Qualidade de ovos comerciais de acordo com a integridade da casca, tipo de embalagem e tempo de armazenamento. 2007. Seropédica, 43p. Dissertação (Mestrado em Zootecnia) - Universidade Federal Rural do Rio de Janeiro.

OLGUN, O.; AYGUN, A. Nutritional factors affecting the breaking strength of bone in laying hens. World's Poultry Science Journal, v. 72 , n. 4 , p. $821-$ 832, 2016. 
PAPAIOANNOU, D.; KATSOULOS, P. D.; PANOUSIS, N.; et al. The role of natural and synthetic zeolites as feed additives on the prevention and/or the treatment of certain farm animal diseases: A review. Microporous and mesoporous materials, v. 84, n. 1-3, p. 161-170, 2005.

PASHA, T. N.; MAHMOOD, A.; KHATTAK, F. M.; et al. The effect of feed supplemented with different sodium bentonite treatments on broiler performance. Turkish Journal of Veterinary and Animal Sciences, v. 32, n. 4, p. 245-248, 2008.

PAWAR, R. R.; BAJAJ, H. C.; LEE, S. M. Activated bentonite as a low-cost adsorbent for the removal of $\mathrm{Cu}$ (II) and $\mathrm{Pb}$ (II) from aqueous solutions: Batch and column studies. Journal of Industrial and Engineering Chemistry, v. 34, p. 213-223, 2016.

POULSEN H. D.; OKSBJERG, N. Effects of dietary inclusion of a zeolite (clinoptilolite) on performance and protein metabolism of young growing pigs. Animal Feed Science and Technology, v. 53, n. 3-4, p. 297-303, 1995.

ROSTAGNO, H. S.; ALBINO, L. F. T.; DONZELE, J. L.; et al. Tabelas brasileiras para aves e suínos: Composição dos alimentos e exigências nutricionais. Viçosa: UFV, 2011. 252 p.

ROSTAGNO, H. S.; ALBINO, L. F. T.; HANNAS, M. I.; et al. Tabelas brasileiras para aves e suínos: Composição dos alimentos e exigências nutricionais. Viçosa: UFV, 2017. 483 p.

RUNHO, R. C.; GOMES, P. C.; ROSTAGNO, H. S.; et al. Exigência de fósforo disponível para frangos de corte machos e fêmeas de 1 a 21 dias de idade. Revista Brasileira de Zootecnia, v. 30, n. 1, p. 187-196, 2001.
SAFAEIKATOULI, M.; JAFARIAHANGARI, Y.; BAHARLOUEI, A. An evaluation on the effects of dietary kaolin and zeolite on broilers blood parameters, T4, TSH and growth hormones. Pakistan Journal of Nutrition, v. 10, n. 3, p. 233-237, 2011.

SAFAEIKATOULI, M.; BOLDAJI, F.; DASTAR, B.; et al. Growth response and tibia bone characteristics in broilers fed diets containing kaolin, bentonite and zeolite. Journal of Animal and Feed Sciences, v. 21, n. 2, 2012.

SAKOMURA, N. K.; ROSTAGNO, H. S. Métodos de pesquisa em nutrição de monogástricos. Jaboticabal: Funep, 2016, 262 p.

SANNI, C. O. Evaluation of techniques for improving phosphorus utilisation in meat poultry. 2017, Nottingham, 275f. Tese (Doctor of Philosophy), Nottingham Trent University.

SCHNEIDER, A. F.; ZIMMERMANN, O. F.; GEWEHR, C. E. Zeolites in poultry and swine production. Ciência Rural, v. 47, n. 8, 2017.

SCHNEIDER, A. F.; MAYER, J. K.; VOLPATO, J.; et al. Minerais séricos, características morfométricas ósseas e deposição de minerais ósseos de frangos de corte alimentados com dieta com inclusão de bentonita. Arquivo Brasileiro de Medicina Veterinária e Zootecnia, v. 71, n. 2, p. 594-602, 2019

SEEDOR, J. G.; QUARTUCCIO, H. A.; THOMPSON, D. D. The bisphosphonate alendronate (MK-217) inhibits bone loss due to ovariectomy in rats. Journal of Bone and Mineral Research, v. 6, n. 4, p. 339-346, 1991.

SHIM, M. Y.; KARNUAH, A. B.; MITCHELL, A. D.; et al. The effects of growth rate on leg morphology and tibia breaking strength, mineral density, mineral content, and bone ash in broilers Poultry Science, v. 91, n. 8, p. 17901795, 2012. 
SIBBALD, I. R.; SLINGER, S. J. A biological assay for metabolizable energy in poultry feed ingredients together with findings which demonstrate some of the problems associated with the evaluation of fats.. Poultry Science, v.42, n.1, p.13-25, 1963.

SOUZA, D. S., CALIXTO, L. F. L., LEMOS, M. J; et al. Inclusion of kaolin in the feed of Japanese quails during the production phase. Revista Colombiana de Ciencias Pecuarias, v. 32 , n. 4, 2019

SUBRAMANIAM, M. D.; KIM, I. H. Clays as dietary supplements for swine: A review. Journal of Animal Science and Biotechnology, n. 1, p. 7, 2015.

ŚWIĄTKIEWICZ, S.; KORELESKI, J.; ARCZEWSKA, A. Laying performance and egg shell quality in laying hens fed diets supplemented with prebiotics and organicacids. Czech Journal of Animal Science, v. 55, n. 7, p. 294-304, 2010.

TRCKOVA, M.; MATLOVA, L.; DVORSKA, L.; et al. Kaolin, bentonite, andzeolites as feedsupplements for animals: healthadvantagesandrisks. A review. Veterinarni Medicina, v.49, p. 389-399, 2004.

USTUNDAG, A. O; OZDOGAN, M. Effects of Feed Additives Used As an Alternative to Antibiotics on Mineral Absorption and Bone Characteristics in Poultry: A Review. Hayvansal Üretim, v. 59, n. 1, p. 79-85, 2018.

WANG, J. P.; CHI, F.; KIM, I. H. Effects of montmorillonite clay on growth performance, nutrient digestibility, vulva size, faecal microflora, and oxidative stress in weaning gilts challenged with zearalenone. Animal Feed Science and Technology, v. 178, n. 3-4, p. 158166, 2012.

YALÇIN, S.; GEBEŞ, E.S.; ŞAHIN, A.; et al. Sepiolite as a feedsupplement for broilers. Applied Clay Science, v. 148, p. 95-102, 2017.

ZENEBON, O.; PASCUET, N. S.; TIGLEA, $P$. Métodos Físico-químicos para Análise de Alimentos. Núcleo de Informação e Tecnologia, São Paulo: Instituto Adolfo Lutz, 2008. 1000p.

ZIMMERMANN, O. F. Zeólitas naturais na alimentação de suínos em crescimento e terminação. 2014. Lages, 86f. Dissertação (Mestrado em Ciência Animal) - Programa de Pós-graduação em Ciência Animal, Universidade do Estado de Santa Catarina. 